\title{
Examining Nutrient Intakes and Academic Performance in Young Irish Twins
}

\begin{abstract}
Introduction: Appropriate nutrition is vital for growth and cognitive development in childhood. Vitamin D, omega 3, zinc, iodine, and iron are important micronutrients for neurodevelopment ${ }^{(1)}$. National survey data suggest that children in Ireland are not meeting recommended intakes of these key nutrients ${ }^{(2)}$. The aim of this research was to determine mean daily intakes of vitamin D, omega 3 , zinc, iodine, and iron among school-aged children and examine the relationship between intakes and academic performance.
\end{abstract}

Materials and Methods: Anthropometric and dietary data was collected from pairs of twins. Four-day food diaries were used by parents to record all food, drinks and supplements consumed. Diaries were entered into the analytical software, Nutritics, which provided the nutrient content of foods consumed. Academic performance was assessed using an online questionnaire. Teachers were asked to rank the child's performance in reading, writing, maths and overall performance using a 5-point likert scale, which was then categorised into "Average" and "Above Average". SPSS V24 was used for statistical analysis.

Results: Data was collected from 51 pairs of twins aged $8-10$ years, and $60 \%$ of participants were female. Mean nutrient intakes were as follows; vitamin $\mathrm{D}=2.34 \mu \mathrm{g}(\mathrm{SD}=1.71)$, omega-3 $=0.68 \mathrm{~g}(\mathrm{SD}=0.43)$, zinc $=7.93 \mathrm{mg}(\mathrm{SD}=3.56)$, iodine $=140.82 \mu \mathrm{g}(\mathrm{SD}=59.26)$ and iron $=9.76 \mathrm{mg}(\mathrm{SD}=3.050)$. All children met recommendations for iodine compared to iron $(61 \%)$, zinc $(52 \%)$ omega-3 $(15 \%)$, and vitamin D (11\%). Supplements contributed to $68 \%$ and $25 \%$ of vitamin D and omega 3 intakes. Meat was the largest contributor to zinc and iron. Milk contributed to $\sim 80 \%$ of iodine intakes. Intra-twin correlations indicated a strong familial effect on nutrient intakes. Children who were ranked "above average" in all categories had significantly higher zinc and iodine intakes compared to average students.

Discussion: The findings of this study concurred with previous analysis of nutrient intakes of Irish and UK children. Animal source foods including meat and milk contributed a high proportion to intakes of key nutrients. Children ranked above average in school had higher nutrient intakes. Public health initiatives should emphasise the importance of key nutrients related to cognitive development and subsequent academic outcomes.

\section{Conflict of Interest}

There is no conflict of interest.

\section{References}

1. Fernando Gómez-Pinilla (2008) Brain foods: the effects of nutrients on brain function. Nature Reviews Neuroscience 9(7), 568-78.

2. Irish Universities Nutrition Alliance. National Children's Survey 2003-2004. Irish National Food Consumption Surveys. 2004. 